\title{
Advokat Dan Pemberantasan Korupsi
}

\author{
Erman Rajagukguk \\ Fakultas Hukum UI Jakarta \\ e-mail : ermanradjagukguk@yahoo.com
}

\begin{abstract}
The role of advocates is of significant importance in the corruption eradication, especially in the side of litigation process. During litigation process, there is ethical dilemma experienced by such advocates in accomplishing advocacy on behalf of the client. In such situation, the courage of an advocate in holding up the Advocate Ethical Codes is very demanding.
\end{abstract}

Keywords: Advocate, Corruption Eradication

Pengertian korupsi dalam arti luas termasuk penyalahgunaan wewenang atau jabatan untuk memperkaya diri sendiri atau orang lain, penggelapan, penyuapan dan pencucian uang. Advokat dapat menjadi saluran untuk melahirkan korupsi, tetapi juga dapat sebagai individu yang dapat memberantas korupsi. Paragrap-paragrap berikut ini akan menguraikan bagaimana seorang advokat dapat ikut memberantas korupsi di tiga jalur kegiatan yang menjadi pekerjaan advokat sehari-hari: konsultan hukum, litigasi, dan pemberantasan pencucian uang.

\section{Pengurusan Non Litigasi (Konsultan Hukum)}

Advokat pada umumnya juga berperanan sebagai konsultan hukum. Konsultan hukum sehari-harinya berhubungan dengan birokrasi pemerintah yang bertugas untuk memberikan berbagai izin yang diperlukan guna menjalankan usaha. Dalam banyak hal, untuk memperlancar pengurusan izin itu harus mengeluarkan biaya yang tak terduga. Jumat pagi kemarin surat kabar memberitakan seseorang yang mau membuka perkebunan Jati Emas di Bojonegoro di atas tanah seluas 4 ha dan mengeluarkan modal Rp. 200 juta. Namun pengurusan izin untuk usaha tersebut akan memakan biaya sampai Rp. 50 juta. Mendengar biaya perizinan yang demikian tinggi orang tersebut tidak jadi memulai 
usahanya. ${ }^{1}$ Ini adalah gejala yang umum di negara kita bagaimana pengurusan perizinan tersebut tidak murah dan tidak cepat. Kalau mau cepat pengurusan perizinan itu akan memakan biaya tinggi.

Perusahaan besar untuk memenangkan tender tidak jarang mengeluarkan biaya, dengan perkataan lain harus mengeluarkan uang suap. Oleh karena praktek-praktek semacam ini Congress Amerika Serikat, umpamanya, mengeluarkan Foreign Corrupt Practices Act (FCPA) tahun 1977. Undang-Undang ini melarang perusahaan-perusahaan Amerika di luar negeri untuk melakukan penyuapan guna memenangkan tender atau kegiatan bisnis mereka. ${ }^{2}$

Berikut ini satu kasus yang menarik berkaitan dengan sebuah perusahaan Amerika yang melakukan kegiatan di Indonesia. Perkara SEC v. KPMG Siddharta \& Harsono menguraikan bagaimana Security Exchange Commission-SEC (Badan Pengawas Pasar Modal) Amerika menuntut Kantor Akuntan Indonesia dengan tuduhan melakukan suap berkaitan dengan pembayaran pajak. Instansi pajak Indonesia memperingatkan anak perusahaan Baker Hughes, PT Eastman Christiensen (PTEC) untuk membayar pajak US\$ 3,2 juta. PTEC menunjuk KPMG Siddharta \& Harsono (KPMG-SSH) untuk mewakili perusahaan tersebut dikantor pajak. KPMG-SSH sependapat dengan pandangan PTEC bahwa pejabat pajak telah keliru, sebaliknya PTEC harus mendapatkan pengembalian pajak. KPMG-SSH bertemu dengan pejabat pajak dari Direktorat Jenderal Pajak dimana pejabat tersebut meminta pembayaran \$ 200.000 sebagai imbalan pengurangan pajak. KPMG-SSH menghubungi Manager Pajak Baker Hughes Asia-Pacific untuk tidak membayar suap tersebut, tetapi menentang tagihan pajak tersebut secara hukum.

Namun demikian, pejabat tersebut tidak menerimanya, walaupun dia sudah menurunkan permintaan menjadi \$75.000. Sonny Harsono, senior partner kantor akuntan tersebut membuat rencana, jika Baker Hughes mau, KPMG-SSH akan membayar pejabat-pejabat pajak tersebut dan memasukkan pembayarannya ke dalam biaya kantor akuntan. Kantor akuntan memberikan dua pilihan kepada PTEC membayar \$ 3,2 juta pajak secepatnya dan akan memakan waktu dua tahun untuk mengatasi masalah tersebut, atau membayar uang suap. Manager pajak Baker Hughes menyampaikan situasi tersebut secara detail kepada Vice President

1 "Perizinan Usaha dan Investasi," Kompas, 16 Mei 2008.

${ }^{2}$ Oren Gleich dan Ryan Woodward, "Foreign Corrupt Practices Act", American Criminal Law Review, Spring, 2005, hlm. 546. 
Baker Hughes sebagai pengawas di Houston dan penasehat kepatuhan FCPA Baker Hughes di Washington D.C, mengingatkan pejabat pajak memberikan waktu kepada PTEC hanya 48 jam untuk menjawab tagihan pajak yang jumlahnya \$3,2 juta. Penasehat FCPA memberitahukan kepada pengawas dan manager pajak PTEC, bahwa pembayaran semacam itu akan melanggar FCPA dan KPMG-SSH harus membuat secara tertulis jaminan bahwa ia tidak akan melakukan hal tersebut.

Pengawas menyampaikan situasi tersebut kepada General Counsel (penasehat hukum) Baker Hughes dan kepala keuangan Baker Hughes. Penasehat hukum menginstruksikan pejabat keuangan dan pengawas untuk tidak mengikuti skema pembayaran suap tersebut. Mengenyampingkan instruksi itu pejabat keuangan dan pengawas mengikuti skema yang ditawarkan dan tagihan pajak turun menjadi \$ 200.000. Penasehat hukum Baker Hughes menemukan apa yang telah terjadi dan secepatnya melakukan tindakan koreksi. Ia berusaha untuk menyetop pembayaran selanjutnya, memberitahukan SEC dan Departemen Kehakiman Amerika, membuka informasi tersebut kepada auditor luar, mengoreksi akuntansi yang tidak betul, memberhentikan KPMG-SSH, menerima pengunduran diri karyawan yang bertanggung jawab, dan membayar kepada Pemerintah Indonesia tagihan pajak yang benar sebesar \$2,1 juta.

Pada tahun 2001 SEC dan Departemen Kehakiman Amerika untuk pertama kali, secara bersama-sama melakukan gugatan perdata kepada KPMG-SSH dengan tuduhan telah melanggar FCPA. Perkara ini menunjukkan bagaimana FCPA berlaku extraterritorial (di luar wilayah Amerika). Perkara ini juga menunjukkan bagaimana seorang penasehat hukum mencegah penyuapan yang termasuk tindakan korupsi. ${ }^{3}$

Kasus lain yang menarik menyangkut anak perusahaan Amerika di Indonesia, adalah PT. Triton Indonesia yang juga mencoba menyuap pejabat Indonesia untuk menurunkan tagihan pajak kepada perusahaan tersebut. Dalam perkara SEC v. Triton Energy Corp. SEC dalam hal ini telah menuntut induk perusahaan tersebut Triton Energy Corporation turut bertanggung jawab bagi dua pejabat anak perusahaannya di Indonesia yang menyuap pejabat pajak. ${ }^{4}$

${ }^{3}$ Daniel Patrick Ashe, "The Lengthening Anti-Bribery Lasso Of The United States : The Recent Extraterritorial Application Of The U.S. Foreign Corrupt Practice Act", Fordham Law Review, May, 2005, hlm. 2921-2931.

${ }^{4}$ Alexandros Zervos, "Amending The Foreign Corrupt Practices Act : Repealing 


\section{Peranan Advokat Dalam Pemberantasan Korupsi Pada Proses Litigasi}

Advokat dalam proses litigasi secara sadar menghadapi dilema etika yang mungkin timbul dalam mewakili kliennya. Dalam perkara perdata memberikan sesuatu kepada hakim bukan tanpa kemungkinan untuk memenangkan perkara. Begitu juga dalam perkara pidana, mulai dari pemeriksaan di kepolisian, kejaksaan dan di depan Pengadilan, pemberian kepada mereka untuk meringankan, bahkan membebaskan tersangka atau terdakwa, di negeri kita, bukan hal yang tidak mungkin. Advokat mempunyai kewajiban untuk memegang kode etik untuk tidak menyuap penegak hukum. Namun para advokat sadar, kalau tidak memberikan, perkaranya akan kalah. Cukup banyak pemberitaan di surat-surat kabar tentang polisi, jaksa, dan hakim yang meminta imbalan berkenaan dengan perkara yang mereka tangani. Advokat yang kuat akan menghindar dari perbuatan yang tercela tersebut.

Peranan advokat sangat penting untuk memberantas korupsi di bidang litigasi. Hal ini semakin penting lagi bila advokat Indonesia mewakili klien luar negeri.

"The net result of these developments is that international legal practitioners not only are going to be at the forefront of the developing anti-bribery mechanisms, but will also be more often challenged by them. So long as clients tread the fine line that separates legality from bribery, lawyer will have to reply on the ethical principles contained in the professional rules of conduct... In the end, as is the case in other legal areas, there is no substitute for professional and ethical judgment". ${ }^{5}$

Oleh karena itu Advokat Indonesia harus memegang teguh Kode Etik Advokat.

\section{Peranan Advokat Dalam Pemberantasan Pencucian Uang}

Rancangan Undang-Undang (RUU) Anti Pencucian Uang yang baru untuk menggantikan Undang-Undang Nomor 25 Tahun 2003 tentang Tindak Pidana Pencucian Uang telah disampaikan ke DPR. Salah satu

The Exemption For “Routine Government" Payment", Penn State International Law Review, Summer, 2006, hlm. 261-261.

${ }^{5}$ Juscelino F. Colares, "The Evolving Domestic \& International Law Against Foreign Corruption: Some New \& Old Dilemmas Facing the International Lawyer" , 5 Washington University Global Studies Law Review, 2006, hlm. 30. 
yang penting bagi kaum profesional dalam RUU ini adalah memasukkan kewajiban Pengacara, Akuntan dan Notaris untuk melaporkan transaksi keuangan yang mencurigakan kepada PPATK.

Uraian berikut ini adalah mencoba membahas kontroversi mengenai kewajiban pengacara untuk melaporkan identitas dan transaksi kliennya di Amerika Serikat dan Eropa.

Pada bulan Mei 2002, FATF menerbitkan "Gatekeeper Initiative" mengusulkan profesi hukum bekerjasama dengan lembaga penegak hukum untuk memonitor pasar keuangan internasional. Proposal tersebut mewajibkan pengacara menyampaikan "laporan transaksi yang mencurigakan".

Sebagai jawaban usul FATF tersebut, American Bar Association menyetujui resolusi yang menentang undang-undang atau peraturan yang akan memaksa pengacara melaporkan informasi dari kliennya yang bersifat rahasia kepada pejabat pemerintah sebagai bagian dari kebijakan internasional melawan pencucian uang. Sebaliknya, resolusi tersebut menyetujui "reasonable and balanced initiatives" untuk mendeteksi dan mencegah pencucian uang dan terorisme. Rekomendasi ABA menyatakan: ${ }^{6}$

"that any changes in policy or regulations targeted at money laundering be consistent with the following principle: that lawyers play a critical and independent role in preserving lawful compliance of persons involved in commerce and finance, that regulation of professional responsibility of lawyers is the responsibility of the judiciary and the organized bar, and that lawyerclient confidentiality is critical to "ensure the independence of the bar, to protect the lawyer-client relationship, and to support the proper functioning of the legal system".

European Union melakukan amandemen "Directive 1991", memperluas kewajiban melaporkan transaksi yang mencurigakan diluar perbankan ke profesi pengacara dan akuntan. Di Inggris sasaran The Criminal Justice Act 1988, Section 93 c memasukkan disamping orang-orang bank, juga pengacara dan akuntan. ${ }^{7}$

Dalam usaha melibatkan pengacara memberantas pencucian uang, selain adanya Undang-undang yang mencantumkan pengacara

'Steven Wechsler, "Professional Responsibility", 54 Syracuse Law Review, 2004, hlm. 1355.

${ }^{7}$ Andreas Rneda, "International Money Laundering Law Enforcement \& TheUSA Patriot Act of 2001", 10 Michigan State University - DCL Journal of International Law, Summer, 2001, h. 157. Andrew de Lotbinere Mc Dougall, "International Arbitration and Money Laundering", 20 American University International Law Review, 2005, hlm. 1033. 
melaporkan transaksi yang mencurigakan, hal yang sama perlu juga dicantumkan dalam Kode Etik Profesi Pengacara. ${ }^{8}$

Di Canada, Bill C 22 mewajibkan tidak saja lembaga keuangan, tetapi juga pengacara dan akuntan harus melaporkan transaksi keuangan yang mencurigakan. ${ }^{9}$

FATF berpendapat beberapa kegiatan pengacara dapat digunakan oleh para pencuci uang untuk melindungi perbuatan mereka.

"For example, money launderers can take advantage of lawyers' ability to create corporate vehicles, establish trust arrangements, and provide financial advice in complex transaction. Money-launderers can also use lawyers' client account for layering and concealing funds, exploiting the secrecy offered by the legal privilege, and obtaining a veneer of respectability by engaging the service of lawyers". ${ }^{10}$

Di Amerika Serikat, berdasarkan Internal Revenue Code (IRC) section 60501, pengacara wajib melaporkan pada IRS nama-nama klien yang membayar tunai biaya pengacara yang jumlahnya melebihi $\$ 10.000,-$. Namun, Rule 1.6 (a) dari American Bar Associations Model Rules of Professional Conduct melarang membuka "information relating to (the) representation of client".

Dalam pada itu, beberapa pengadilan, dalam mempertimbangkan masalah penyampaian identitas klien, menerapkan bahwa, "general rule that client identification and fee arrangements are not protected by attorney client privilege". Misalnya, dalam United States v. Ritchie, 15F.3d 592 (6 $6^{\text {th }}$ Cir. 1994) Pengadilan menyatakan: "no reason to grant law firms a potential monopoly on money laundering solely because theirs services are personal and confidential".

Dalam perkara lain dalam Alexior v. United States, 39F.3d 973 (9 $9^{\text {th }}$ Cir, 1994), Pengadilan menyatakan tidaklah menjadi rahasia nama klien yang membayar pengacaranya dengan uang palsu \$ 100. Pengadilan berpendapat bisa ada kekecualian terhadap ketentuan umum dengan

${ }^{8}$ Katrina R. Abendano, "The Rule of Lawyers in the Fight Against Money Laundering is a Reporting Requirement Appropriate", 27 Journal of Legislation, 2001, hlm. 474.

${ }^{9}$ Kevin Moran, "Global Banking - Canada / Latin Amrica / Afrika” 20 Annual Review of Banking Law, 2001, hlm. 84-85.

${ }^{10}$ Patricia Shaughtessy, "The New EU Money-Laundering Directive : Lawyers AS Gate-Keeper and Whistle - Blowers," 34 law and Policy in International Business, 2002, hlm. 30-31. 
mengatakan: "if the client's identification was a last link tying the client to a crime and found that "the client's identity would not suffice in this case; knowledge and intent would still have to be proved."

Dalam perkara lainnya United States v. Gartner \& Newman, 873 F. Supp. 729 (D. Mass 1995), Pengadilan District Massachusetts menyatakan kekecualian lain dari Ketentuan Umum, dengan memutuskan, “... where there was concrete evidence that disclosure of a client's identity, despite his paying more than \$10,000. in cash, was privileged nevertheless".

Berdasarkan ketentuan umum, pengacara secara tak terbatas menyampaikan informasi seperti tersebut di atas. Hal ini menghasilkan erosi yang potensial bagi pengacara untuk mewakili kliennya dengan benar dan efektif. Selanjutnya masyarakat akan menanggung akibat dari ketakutan klien dituntut akibat informasi rahasia yang dibukakan oleh pengacaranya.

Di samping masalah identitas klien, para pengacara di Amerika juga merasa khawatir akan diminta bertanggungjawab dalam potensi keikutsertaan mereka dalam pencucian uang.

Adalah Benar pengacara dapat menjadi tempat yang subur bagi pencucian uang, karena, "lawyers are especially attractive to money launderers because their professional conduct rules force them to keep clients secrets".

Strategi memberantas pencucian uang mewajibkan pengacara dan akuntan ikut serta dalam usaha-usaha tersebut, menganggap bahwa kedua professi ini dapat memainkan peranan sebagai penjaga pintu dalam transaksi keuangan domestik maupun internasional.

Namun demikian pengharapan menjadi "penjaga pintu" itu, bisa membawa akibat negatif bagi profesi pengacara. Pertama, hak klien untuk mendapatkan kerahasian secara serius akan menjadi kompromistis sifatnya. Kedua, Pemerintah dapat menerapkan sanksi pidana kepada para pengacara. ${ }^{11}$

Setidak-tidaknya ada empat fungsi pengacara dalam hubungannya dengan klien, termasuk:1). advisors clients; 2). screening cases and legal arguments; 3). avoiding personal participation in improper behavior, and 4). disclosing confidences, when permitted by rule, to serve interests that trump the client's. ${ }^{12}$

${ }^{11}$ Sally Baghdasarian, "Gatekeepers : How the Broad Application of Anti-Money Laundering Statutes and Strategies May Open an Attorney's Gates to Prosecutions", 32 Southwestern University Law Review, 2003, hlm. 726-731.

${ }^{12}$ Fred Zacharias, "Lawyers As Gatekeepers", 41 San Diego Law Review, August - Sept 2004, hlm. 1390. 
"European Union Directive" terdiri dari dua unsur: (1) identifikasi dan (2) keterbukaan. Pertama, ketentuan mengenai identifikasi mewajibkan pengacara melakukan "due deligence investigation" terhadap kliennya. Ketentuan ini dikenal dengan "know-your-client", mewajibkan pengacara mengetahui siapa yang sebenarnya mendapat manfaat dari jasa pengacara itu, bukan semata-mata yang tampak di depan matanya, atau orang yang datang kepadanya.

Untuk mengetahui hal tersebut dapat dimafaatkan kesempatankesempatan berikut ini: "(1) when entering into a business relationship with a client; (2) when opening a client account; (3) when offering safe custody facilities; or (4) when any transaction involves currency 15,000 or more, whether in single sum or separate installments."

Kedua, laporan harus dibuat bila ada transaksi yang mencurigakan.

Ketentuan-ketentuan di atas tentu menimbulkan kontroversi berkenaan dengan konsep "independent legal professional" dan "attorneyclient-privilege" yang bersifat rahasia (confidential).

\section{Penutup}

Hubungan istimewa pengacara dan klien melindungi lebih dari pada privasi klien. Hubungan tersebut harus menegakkan "public administration of justice". Oleh karena itu pengacara juga harus meneliti identitas kliennya, dari mana dana berasal dan motifnya untuk meminta bantuan pengacara.

Kewajiban pengacara untuk melaporkan bila mencurigai adanya kegiatan pencucian uang. Hal ini tentu tidak mudah, apalagi, kuat sekali pendirian pengacara bahwa ia harus merahasiakan pembicaraan dengan klien atau penemuan yang bisa memberatkan kliennya.

\section{Daftar Pustaka}

Abendano, Katrina R. The Rule of Lawyers in the Fight Against Money Laundering is a Reporting Requirement Appropriate. 27 Journal of Legislation, 2001.

Ashe, Daniel Patrick. The Lengthening Anti-Bribery Lasso Of The United States: The Recent Extraterritorial Application Of The U.S. Foreign Corrupt Practice Act. Fordham Law Review, May, 2005.

Baghdasarian, Sally. Gatekeepers : How the Broad Application of Anti-Money Laundering Statutes and Strategies May Open an Attorney's Gates to Prosecutions. 32 Southwestern University Law Review, 2003. 
Colares, Juscelino F. The Evolving Domestic \& International Law Against Foreign Corruption: Some New \& Old Dilemmas Facing the International Lawyer. 5 Washington University Global Studies Law Review, 2006. Gleich, Oren \& Ryan Woodward. Foreign Corrupt Practices Act. American Criminal Law Review, Spring, 2005.

Mc Dougall, Andrew de Lotbinere. International Arbitration and Money Laundering. 20 American University International Law Review 2005. Moran, Kevin. Global Banking - Canada / Latin Amrica / Afrika. 20 Annual Review of Banking Law, 2001.

Rneda, Andreas. International Money Laundering Law Enforcement $\mathcal{E}$ The USA Patriot Act of 2001. 10 Michigan State University - DCL Journal of International Law, Summer, 2001.

Shaughtessy, Patricia. The New EU Money-Laundering Directive : Lawyers AS Gate-Keeper and Whistle - Blowers. 34 law and Policy in International Business, 2002.

Wechsler, Steven. Professional Responsibility. 54 Syracuse Law Review 2004. Zacharias, Fred. Lawyers As Gatekeepers. 41 San Diego Law Review, August - Sept 2004.

Zervos, Alexandros. Amending The Foreign Corrupt Practices Act: Repealing The Exemption for "Routine Government" Payment. Penn State International Law Review, Summer, 2006.

"Perizinan Usaha dan Investasi," Kompas, 16 Mei 2008. 